\title{
The suppressing effects of BTG3 expression on aggressive behaviors and phenotypes of colorectal cancer: An in vitro and vivo study
}

\author{
Hua-Chuan Zheng ${ }^{1}$, Hao-Yu He ${ }^{1}$, Ji-Cheng Wu${ }^{1}$, Jing Li $^{2}$, Shuang Zhao ${ }^{1}$, Gui-Feng \\ Zhao', Hua-Mao Jiang ${ }^{2}$, Xue-Wen Yu ${ }^{2}$, Zhi-Jie Li ${ }^{1}$ \\ ${ }^{1}$ Department of Experimental Oncology and Animal Center, Shengjing Hospital of China Medical University, Shenyang \\ 110004, China \\ ${ }^{2}$ Jinzhou Medical University, Jinzhou 121001, China \\ Correspondence to: Hua-Chuan Zheng, email: zheng_huachuan@hotmail.com \\ Keywords: colorectal cancer, BTG3, pathobiological behaviors, aggressive phenotypes, gene therapy \\ Received: December 06, $2016 \quad$ Accepted: January 11, $2017 \quad$ Published: February 17, 2017
}

\section{ABSTRACT}

Here, we found that down-regulated expression of BTG3 might be positively correlated with colorectal carcinogenesis and its overexpression suppressed proliferation, glycolysis, mitochondrial respiration, cell cycle progression, migration, and invasion, and induced apoptosis, senescence and differentiation in SW480 and SW620 cells. After treated with cisplatin, MG132, paclitaxel and SAHA, BTG3 transfectants exhibited lower viability and higher apoptosis than the control in both time- and dose-dependent manners. BTG3 overexpression up- regulated the protein expression of Cyclin E, p16, p27, NF-kB, p38a/ $\beta$, XIAP, Bcl-2, ATG14 and p53, but down-regulated the mRNA expression of MRP1, BCRP, and $m T O R$ in SW480 and SW620 cells. BTG3 overexpression inhibited tumor growth of SW620 cells by suppressing proliferation and inducing apoptosis. It was suggested that down-regulated BTG3 expression might be considered as a marker for colorectal carcinogenesis. BTG3 overexpression might reverse the aggressive phenotypes and be employed as a potential target for gene therapy of colorectal cancer.

\section{INTRODUCTION}

Colorectal cancer (CRC) is one of the most common cancers in the world and accounts for nearly one-tenth of new cases of all cancers. Although the incidence and mortality have been decreasing in the past two decades due to the alteration in risk factors and colorectal cancer screening, it challenges the health of the human being $[1,2]$. Therefore, it is essential to improve the diagnosis, treatment and prevention via the identification of novel biomarkers and treatment targets.

$B T G 3$ is distributed to human chromosome $21 \mathrm{q} 21.1$ and transcriptionally produces two variants with 132-nucleotide deletion by alternative splicing. Its encoding protein is found to inhibit cell proliferation, cell cycle progression and induce differentiation as a tumor suppressor [3, 4]. BTG3 can interact with E2F1 to suppress the binding of the E2F1-DP1 complex to DNA duplex, resulting in cellular S-phase arrest [5]. BTG3 also interacts with Smad8 receptor- regulated Smad transcription factor
[6], and with src to suppress Ras/MAP kinase signaling [7]. BTG3 can be phosphorylated and activated via the interaction with checkpoint kinase 1 (CHK1). BTG3mediated maintenance of genomic stability requires its Lys63 ubiquitination and CHK1 activation [5, 8]. BTG3 abrogation might enhance bone morphogenetic proteininduced ectopic bone formation [6] and induce lung carcinogenesis [9]. The down-regulated BTG3 expression was attributable to its promoter methylation in breast, lung, prostate or renal, hepatocellular, and gastric cancer tissues or cells [10-15]. The down- regulated BTG3 expression was also found during ovarian carcinogenesis, and positively correlated with the dedifferentiation, FIGO staging, and adverse prognosis of cancers [16]. Yanagida et al. [17] showed that $B T G 3$ knockdown promoted proliferation and tumorigenicity of ovarian clear cell carcinoma. Our group also demonstrated that BTG3 overexpression inhibited proliferation, migration, invasion and tumor growth, induced $\mathrm{S} / \mathrm{G}_{2}$ arrest, differentiation, autophagy, apoptosis and chemosensitivity of gastric cancer cells [18]. 
To clarify the roles of BTG3 in colorectal carcinogenesis and subsequent progression, we investigated the effects of BTG3 overexpression on cell proliferation, glucose metabolism, apoptosis, senescence, differentiation, invasion and migration of CRC cells and screened the expression of the phenotype-related genes. Moreover, we examined the expression of BTG3 mRNA and protein in CRCs, and compared them with clinicopathological parameters of cancers. Its promoter methylation was measured in colorectal cancer cells and tissues. Finally, the in vivo effect of BTG3 overexpression on tumor growth was determined in nude mice bearing CRC cells.

\section{RESULTS}

\section{The effects of BTG3 expression in the phenotypes and relevant molecules of CRC cells}

We observed a comparatively higher expression of BTG3 mRNA in DLD-1, Colo 201, Colo 205, and KM-
12 (Figure 1A). Its promoter methylation was detected in HCT-15, HCT-116, SW480 and SW620 cells (Figure 1B). After treated with 5-Aza, promoter methylation level of BTG3 was weakened, but versa for its mRNA expression in SW480, HCT-15 and HCT-116 cells (Figure 1B, $\mathrm{p}<0.05)$. However, BTG3 protein expression was higher in Colo 205, HT-29, KM-12 and SW480 (Figure 1C). After treated with MG132, HCT-15, HCT-116, SW480 and SW620 cells showed a gradually decreased proliferation in either dose- or time-dependent manner (Figure 1D, $\mathrm{p}<0.05$ ) with an increased BTG3 expression (Figure 1E).

Here, we successfully transfected BTG3-expressing plasmid into SW480 and SW620 cells, evidenced by realtime RT-PCR and Western blot (Figure 2A). Both the transfectants showed a lower growth, evidenced by CCK8 (Figure 2B, $\mathrm{p}<0.05$ ) and a higher apoptosis by Annexin V-FITC staining in BTG3 transfectants than the control and mock (Figure $2 \mathrm{D}, \mathrm{p}<0.05$ ). There appeared $\mathrm{G}_{1}$ arrest in BTG 3-overxpressing SW480 cells in comparison to the control and mock by PI staining, while $\mathrm{S}$ arrest in SW620 cells (Figure 2C). BTG3 overexpression inhibited

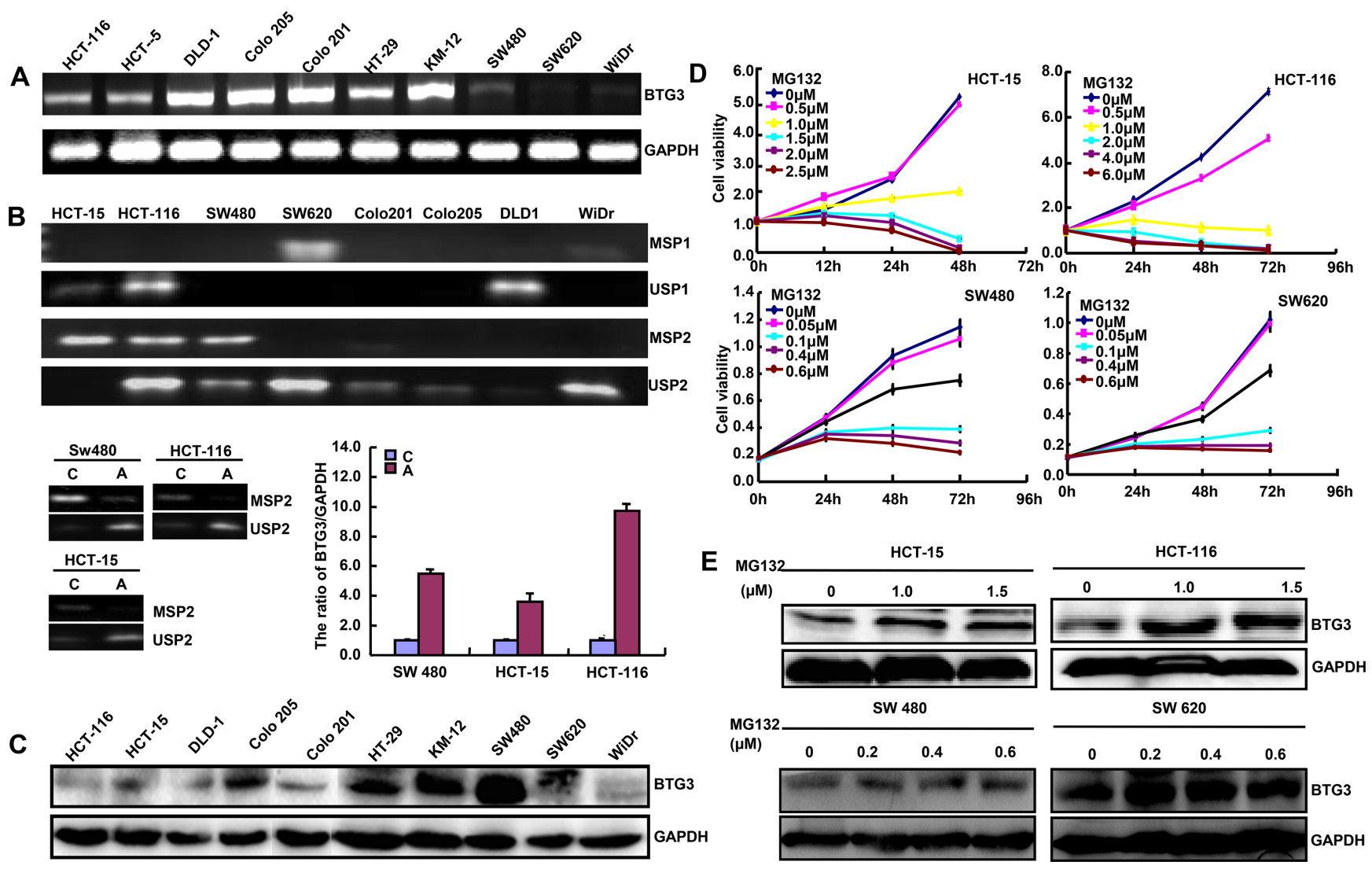

Figure 1: BTG3 expression in colorectal cancer cells. BTG3 mRNA was detected at different levels in colorectal cancer cells with an internal control of GAPDH A. The promoter methylation of BTG3 was screened by methylation-specific PCR (MSP, B). After treated with 5-Aza-Dc, SW480, HCT-15, and HCT-116 cells showed a lower methylation and a higher expression of BTG3 mRNA by RT-PCR than the control B. The protein was loaded and probed by the anti-BTG3 (29kDa) antibody with GAPDH (42 kDa) as an internal control C. After treated with MG132, HCT-15, HCT-116, SW480 and SW620 cells showed a gradually decreased proliferation in either dose- or time-dependent manner D. Additionally, BTG3 expression became higher in the MG132-treated four cells than the control, evidenced by Western blot $\mathbf{E}$. 

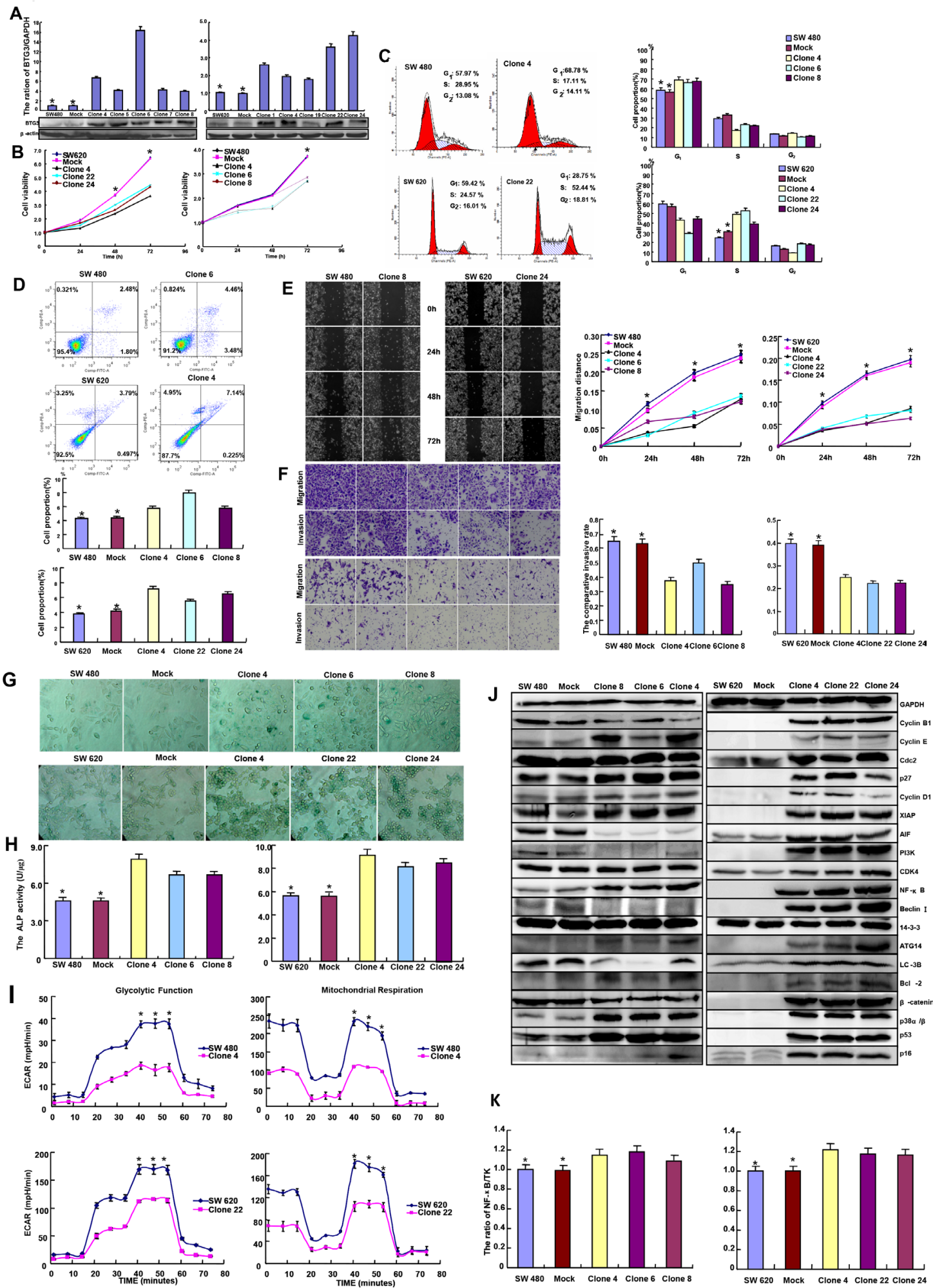

Figure 2: The effects of BTG3 overexpression on the phenotypes and their relevant molecules of colorectal cancer cells. After the transfection of pcDNA3.1-BTG3, its expression became strong in SW480 and SW620 cells by RT-PCR and Western blot A. The transfectants showed a low growth $\mathbf{B}$. and $\mathrm{G}_{1}$ or $\mathrm{S}$ arrest $\mathbf{C}$. in comparison with the control and mock. There was an apoptosis-induced effect of BTG3 overexpression in both transfectants, evidenced by Annexin V assay D. BTG3-overexpressing cells had a weaker ability to migrate and invade by wound healing $\mathbf{E}$. and transwell assays $\mathbf{F}$. BTG3 transfectants showed a higher senescence, a better differentiation, a lower level of glycolysis or mitochondrial function than the control and mock, evidenced by $\beta$-galactosidase staining G., ALP activity H., and metabolism assay I. respectively. The expression of phenotype- related molecules was screened by Western blot $\mathbf{J}$. There was a high activity of NF- $\mathrm{kB}$ promoters in BTG3 transfectants, compared with the control and mock $\mathbf{K}$. Results are representative of 3 different experiments, and data are expressed as mean \pm standard deviation. Note: $\mathrm{NC}$, negative control; * $\mathrm{p}<0.05$, compared with $B T G 3$ transfectants. 
the migration and invasion of CRC cells according to wound healing (Figure 2E, $\mathrm{p}<0.05$ ) and transwell chamber assays (Figure $2 \mathrm{~F}, \mathrm{p}<0.05$ ), but induced senescence and differentiation, evidenced by $\beta$-galactosidase staining (Figure 2G) and alkaline phosphatase (ALP) activity (Figure $2 \mathrm{H}, \mathrm{p}<0.05$ ) respectively. BTG3-overexpressing CRC cells displayed a lower glycolysis and mitochondrial respiration than the mock and control according to oxygen consumption and extracellular acidification rates (Figure 2I, $\mathrm{p}<0.05)$.

As shown in Figure 2J, BTG3 overexpression increased the expression of Cyclin E, Cyclin D1, p16, p27, NF-кB, p38 $\alpha / \beta$, XIAP, Bcl-2, ATG14, and p53 in SW480 and SW620 cells. There was a lower expression of Cyclin B1, AIF, PI ${ }_{3}$, Beclin 1, LC-3B, and $\beta$-catenin in $B T G 3$ transfectants of SW480 than the mock and control, while the converse was true for SW620. Additionally, transcriptional activity of NF- $\kappa \mathrm{B}$ were higher in BTG3 transfectants than the control or mock according to luciferase reporter assay (Figure $2 \mathrm{~K}, \mathrm{p}<0.05$ ). After treated with cisplatin, MG132, paclitaxel and SAHA, BTG3 transfectant exhibited lower viability and higher apoptosis than the control in both time- and dose-dependent manners (Figure 3A-3B, $p<0.05$ ). BTG3 overexpression decreased the expression of $M R P 1, B C R P$, and $m T O R$ in SW480 and SW620 cells (Figure 3C, $p<0.05$ ).

\section{The effects of BTG3 overexpression on the tumor growth of CRC cells in nude mice}

SW620 and its BTG3 transfectant were subcutaneously transplanted into immune-deficient nude mice. As shown in Figure 4A, the tumor volume and weight of both parental cells were larger and heavier than those of BTG3 transfectants by ruling, weighting and capacity measurement respectively $(\mathrm{p}<0.05)$. BTG3 protein was strongly expressed in the cytoplasm of the transfectant, compared with the control. The transfectants showed a low expression of ki-67 (a marker for proliferation) and a strong signal of TUNEL (a marker for apoptosis) in comparison to the control (Figure 4B).

\section{BTG3 expression in CRC tissues}

BTG3 protein was more detected in colorectal nonneoplastic mucosa (NNM) than that in cancer (Figure $5 \mathrm{~A}, \mathrm{p}<0.05)$. The decreased BTG3 mRNA expression was seen in CRC, in comparison with paired NNM (Figure $5 \mathrm{~B}, \mathrm{p}<0.05$ ). It was also verified by laser capture microdissection (LCM) and real-time RT-PCR (Figure $5 \mathrm{C}, \mathrm{p}<0.05)$. The promoter methylation of BTG3 was less frequently detected in CRC than paired NNM (Figure $5 \mathrm{D}, \mathrm{p}<0.05)$. There was no correlation between mRNA expression and promoter methylation of BTG3 in CRCs ( $\mathrm{p}>0.05)$. Then, we used Gaedcke's, Hong's, Skrzypczak's and TCGA's dataset to perform bioinformatical analysis and found that BTG3 mRNA expression was higher in colorectal normal mucosa than adenoma or cancer (Figure $5 \mathrm{E}, \mathrm{p}<0.05)$.

BTG3 protein was distributed in the cytoplasm of colorectal epithelium, infiltrating inflammatory cells, macrophages, hepatocytes, lymphoid follicle, adenoma, and cancers (Figure 6A-6L). BTG3 expression was detectable in colorectal NNM $(46.3 \%, 220 / 475)$, adenoma $(57.9 \%, 73 / 126)$, primary cancer $(82.0 \%, 396 / 484)$, and metastatic cancer in lymph node $(80.0 \%, 120 / 150)$ and liver $(81.0 \%, 17 / 21)$ respectively. BTG3 expression was statistically higher in colorectal cancer and adenoma than adjacent non-neoplastic mucosa $(\mathrm{p}<0.05$, Table 1$)$.

\section{The relationship between BTG3 expression and clinicopathological parameters of CRC}

BTG3 expression was positively correlated with depth of invasion and differentiation of CRCs (Table 2, $\mathrm{p}<0.05)$. Follow-up information was available on 383 CRC patients for periods ranging from 2 days to 10.8 years (median=68.6 months). Kaplan-Meier analysis indicated no difference between the cumulative survival rates of patients and BTG3 expression, even stratified by depth of invasion (Figure 6M, p>0.05). Cox's proportional hazard model indicated that depth of invasion and distant metastasis were independent prognostic factors for overall CRCs (Table 3, $\mathrm{p}<0.05$ ).

\section{DISCUSSION}

In line with the results of oncomine analysis, we found that BTG3 expression was decreased in CRC, compared with adjacent NNM by Western blot and realtime RT-PCR, even followed by LCM. These findings suggested that down-regulated BTG3 expression contributed to the malignant transformation of colorectal epithelial cells, consistent with these documents $[14,15$, $18,19]$. As reported previously [18], only $B T G 3 b$ mRNA was found in colorectal cancer and NNM although BTG3a and $3 b$ were detectable in lung cancer cells and tissues [15]. After the exposure to 5-Aza, CRC cells showed the attenuated promoter methylation and strengthened BTG3 mRNA expression, which was reported in gastric, breast, renal and prostate cancer cells $[10-12,18]$. In combination with no correlation between BTG3 methylation and mRNA expression in CRC, it was speculated that BTG3 methylation was partially responsible for its silenced expression. In contrast, more frequent methylation of BTG3 was found in colorectal mucosa than cancer, similar to its mRNA, while versa for BTG3 immunopositivity. The paradoxical phenomenon might be hypothesized to correlate with BTG3 methylation, weaker BTG3 expression in cytosol-marginal stromal cells, and BTG3 degradation by ubiquitin-proteasome system [20] as demonstrated in the present study. 

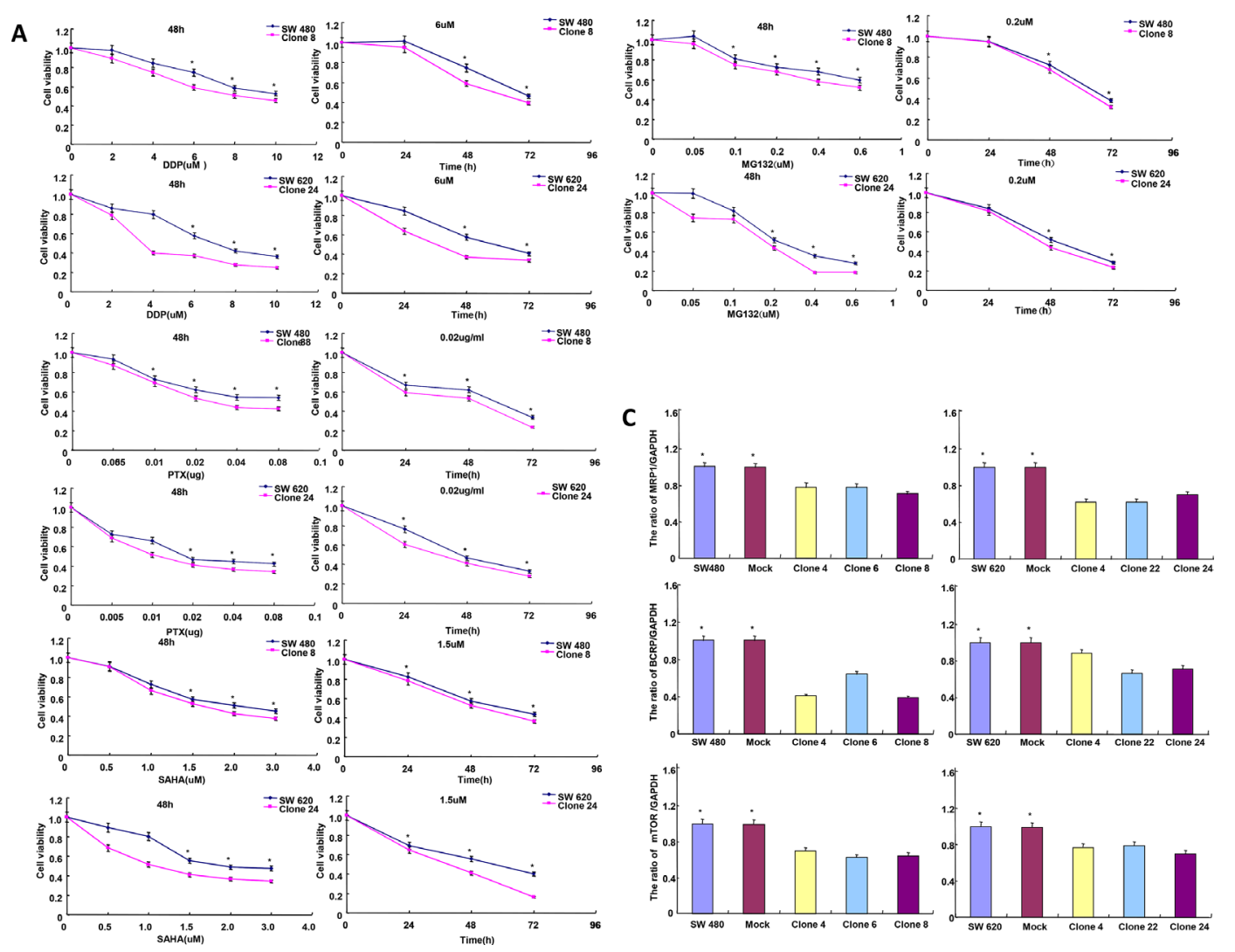

B
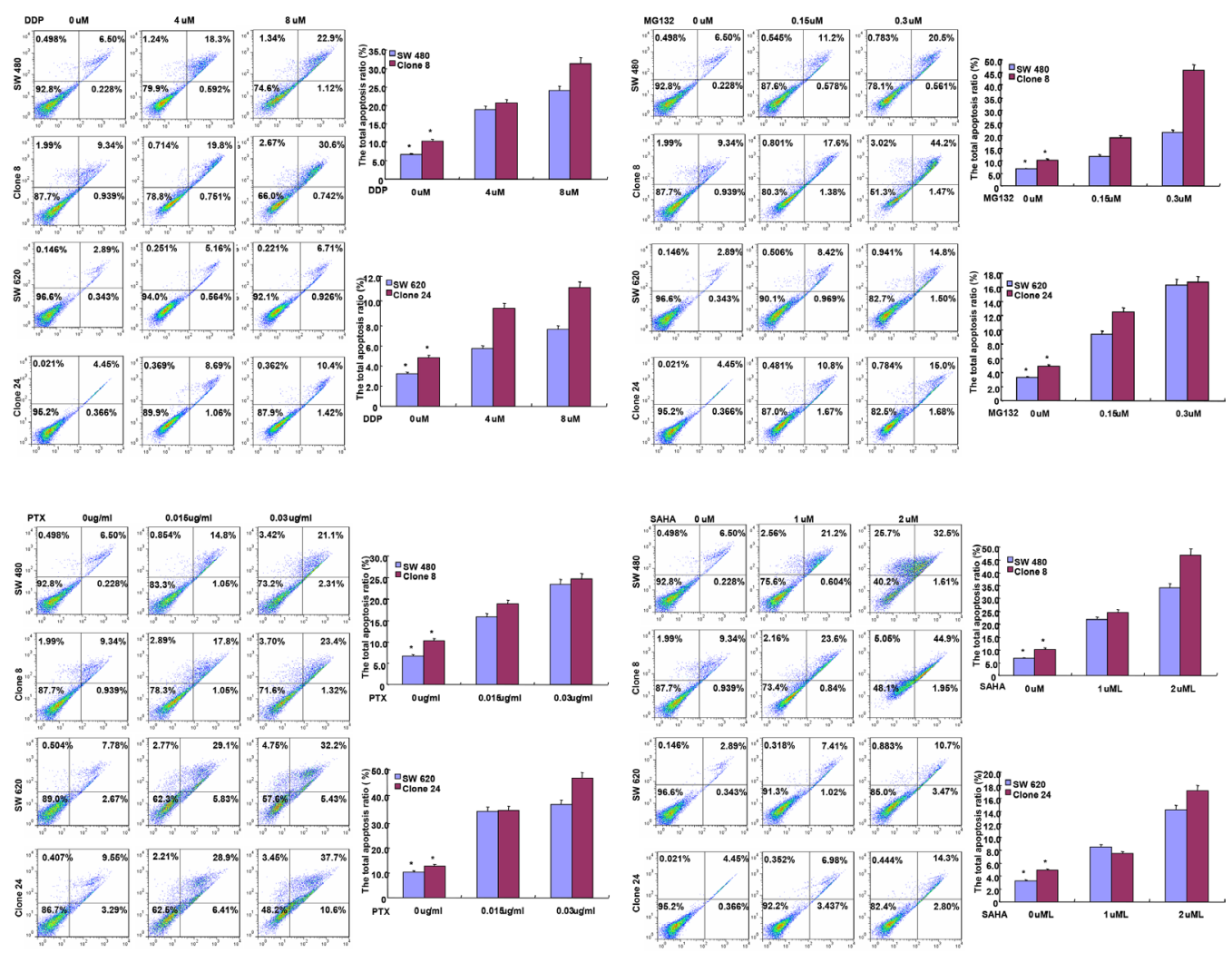

Figure 3: BTG3 expression enhances the sensitivity of colorectal cancer cells to chemotherapeutic drugs. After the exposure to cisplatin (DDP), MG132, paclitaxel (PTX), and SAHA, BTG3 transfectants showed a lower viability and a higher apoptotic level than the control in both concentration- and time-dependent manners $\mathbf{A}$ and $\mathbf{B}$. The chemoresistance-related genes were screened by real-time RT-PCR C. * $\mathrm{p}<0.05$, compared with $B T G 3$ transfectants. 
Here, BTG3 overexpression enhanced ALP level of CRC cells, supporting the positive link between BTG3 overexpression and differentiation of CRCs. There appeared BTG3 overexpression in deeply-invasive cancer, while BTG3 overexpression suppressed proliferation, migration, invasion, tumor growth, glycolysis and mitochondrial respiration with the induction of apoptosis or senescence as the reports about gastric cancer [18], and esophageal adenocarcinoma [19] cells. Ectopic BTG3 expression reversed the aggressive behaviors of gastric cancer and hepatocellular cancer cells in vitro [14], and inhibited the tumor growth of lung and gastric cancers in vivo $[15,18]$. In contrast, Provenzani et al $[21]$ found that $B T G 3$ mRNA had about 1.83 fold higher in primary than metastatic cancer of colon by cDNA microarray. Exogenous BTG3 protein suppresses the levels of MMP-2 and PAI-1 expression in lung cancer cells [9]. Reportedly, BTG3 expression was inversely correlated

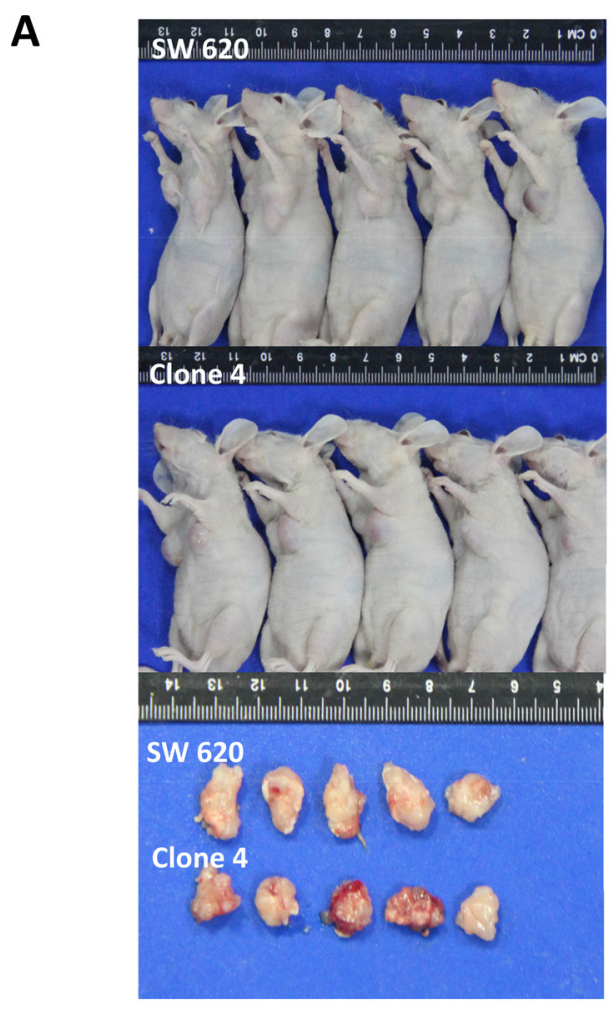

B
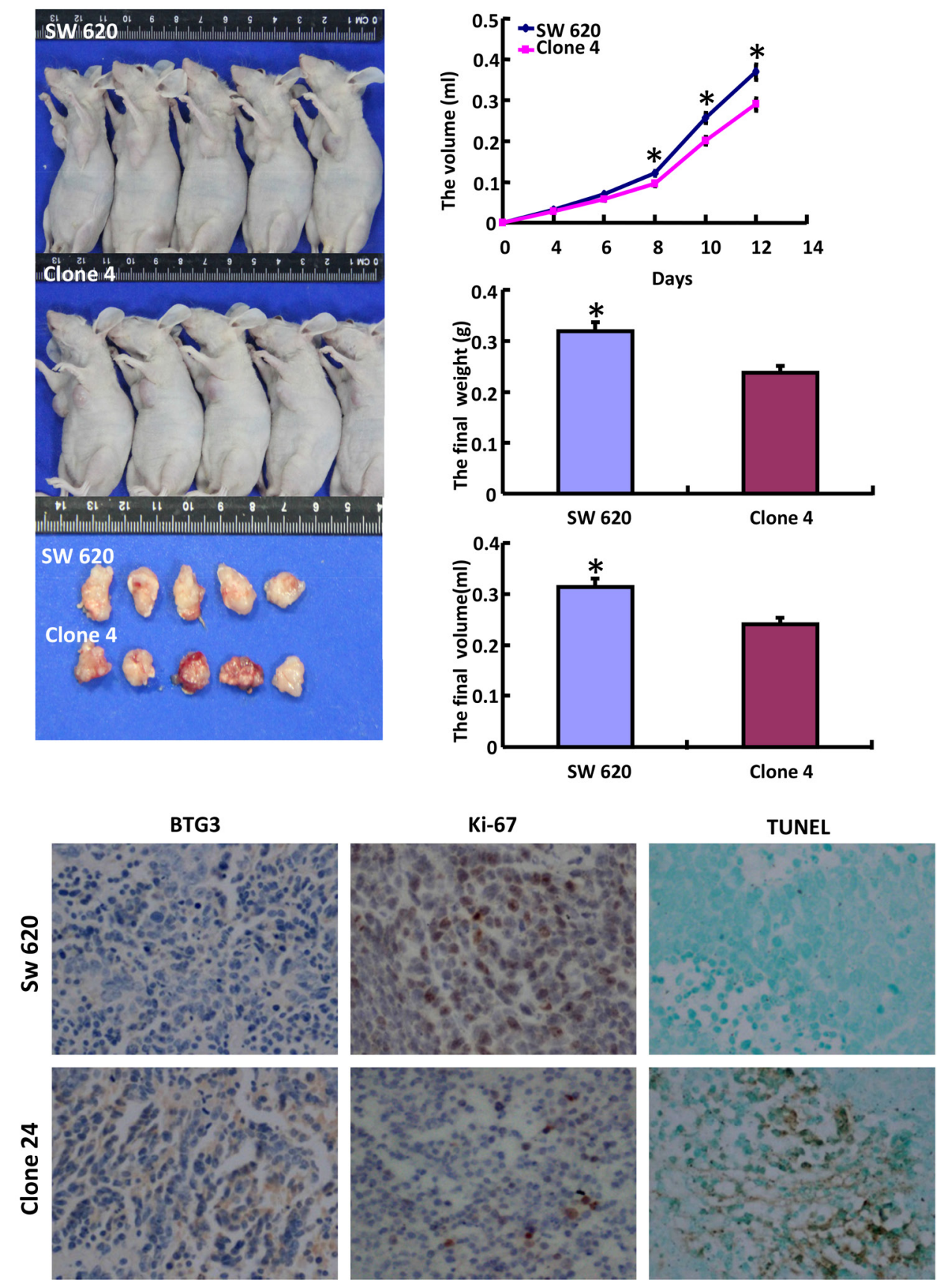

Figure 4: The roles of BTG3 overexpression on the growth of colorectal cancer cells in nude mice. The tumor volume and weight were measured by ruling, weighting and capacity measurement A. Immunohistochemistry was employed for the detection of BTG3 and ki-67 expression, while TUNEL for apoptotic signal $\mathbf{B}$. 
with differentiation, lymph node metastasis, or distant metastasis of esophageal, gastric and hepatocellular cancers $[14,18,19]$. BTG3 binds and suppresses AKT so as to decrease $\beta$-catenin/TCF activity, down-regulate mesenchymal markers, and consequently reduce cell migration and tumor growth [22]. Another report showed that BTG3 overexpression was found to inhibit cell growth, invasion, metastasis and epithelial-mesenchymal transition (EMT), induced cell cycle arrest of SW480 cells via Wnt/ $\beta$-catenin signaling pathway [23]. Therefore, we concluded that BTG3 overexpression might be a feedback reaction and suppress aggressive phenotypes so that it might be employed as a potential target of gene therapy for CRCs.

Furthermore, BTG3 transfectant showed a higher chemosensitivity to cisplatin, MG132, paclitaxel and SAHA, which was positively correlated with a high apoptotic induction. Additionally, BTG3 overexpression results in the mRNA hypoexpression of chemoresistancerelated genes, such as $M R P 1, B C R P$, and $m T O R$. MDR1 and BCRP belong to efflux transporters of the ATP-binding cassette family and pumps many foreign substances out of cells [24]. Chemoresistance is induced or acquired through the activation of the $\mathrm{PI}_{3} \mathrm{~K} / \mathrm{Akt} / \mathrm{mTOR}$ pathway in some malignancies [25]. Taken together, BTG3-mediated chemosensitivity was positively linked to the downregulated expression of the chemoresistance-related genes. However, the detailed mechanisms would be investigated in the future.

Although both SW480 and SW620 cells are separated from primary and lymph node metastasis foci of the same CRC patients, the inconsistent expression of Cyclin B1, AIF, PI K, Beclin 1, LC-3B, and $\beta$-catenin

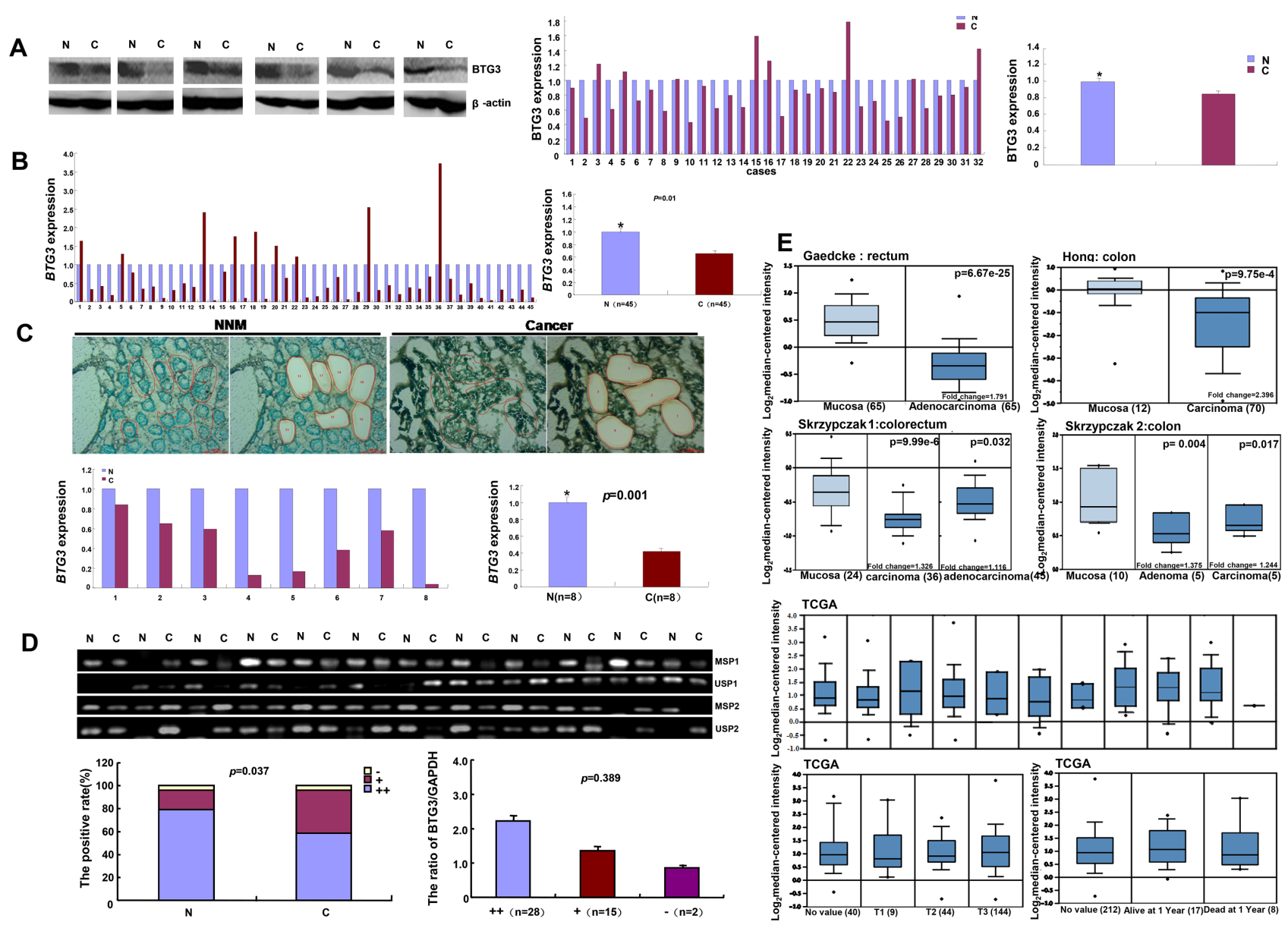

Figure 5: BTG3 expression in colorectal cancer. There was less BTG3 expression in the tissue lysates of colorectal cancer than paired mucosa with $\beta$-actin as an internal control $(\mathrm{p}<0.05$, A.) by Western blot and densometric analysis. BTG3 cDNA was amplified by real-time RT-PCR with GAPDH as an internal control. A lower BTG3 mRNA expression was detected in colorectal cancer than matched mucosa $(\mathrm{p}<$ 0.05 , B.), even followed laser capture dissection ( $<<0.05, \mathbf{C}$.). The higher level of $B T G 3$ methylation was detected in normal mucosa than paired cancer, but no relationship was found between the mRNA expression and promoter methylation of $B T G 3$ in colorectal cancers $\mathbf{D}$. Gaedcke's, Hong's, Skrzypczak's, and TCGA's datasets were employed for bioinformatical analysis to compare BTG3 mRNA expression with the carcinogenesis, TNM staging and prognosis of colorectal cancer E. Note: M, methylated; U, unmethylated; N, non-neoplastic mucosa; $\mathrm{C}$, cancer; $\mathrm{NC}$, negative control; -, negative for methylaiton; +, only one site for methylation; ++, two sites for mehtylation; $\mathrm{p}>$ 0.05 . Data was expressed as mean \pm standard error. 
in BTG3 might underlie the molecular mechanisms of the differences in the biological behaviors of SW480 and SW620, even their BTG3 transfectants. In apoptosis, Bcl2 can interact with Bax on the mitochondrial membrane to suppress the apoptosis [26]. XIAP might function as apoptotic inhibitor by binding to and suppressing caspase activation [27]. The up-regulated expression of both proteins in BTG3 transfectants was demonstrated to not correlate with BTG3-induced apoptosis in CRC cells. According to LC-3B expression, the effects of BTG3 on autophagy were different between SW420 and SW680, and positively linked to Beclin 1 expression, indicating that BTG3-induced autophagy was dependent on Beclin-1 and belonged to canonical pathway. Here, BTG3 overexpression was found to activate NF- $\kappa B$ pathway by up-regulating its transcriptional activity and expression, but its biological effects should be deeply investigated.
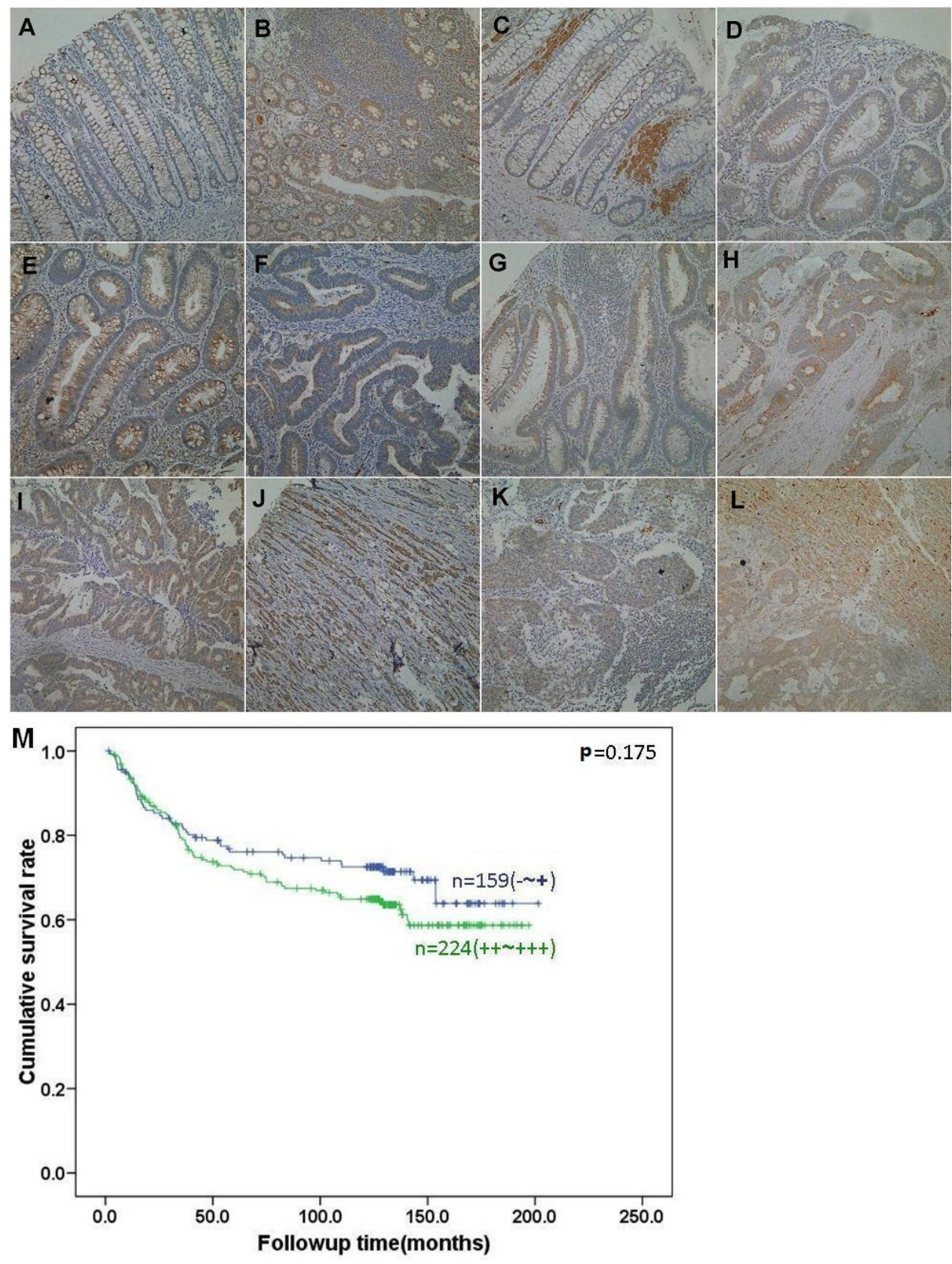

Figure 6: BTG3 expression and its prognostic significance in colorectal cancer. BTG3 protein was positively detected in the cytoplasm of colorectal epithelium A, B., infiltrating inflammatory cells (A), lymphoid follicle (B), macrophages C., adenoma D, E., welldifferentiated F, G., moderately-differentiated $\mathbf{H}$, I., and poorly-differentiated J. adenocarcinoma, metastatic cancers in lymph node K. and liver L., and hepatocytes (L). Kaplan-Meier analysis showed no relationship between BTG3 expression status and the cumulative survival of patients with colorectal cancer $\mathbf{M}$. 
Table 1: BTG3 expression in colorectal carcinogenesis and subsequent progression

\begin{tabular}{|c|c|c|c|c|c|c|}
\hline \multirow{2}{*}{ Groups } & \multirow{2}{*}{$\mathbf{n}$} & \multicolumn{5}{|c|}{ BTG3 expression } \\
\hline & & - & + & ++ & +++ & PR (\%) \\
\hline Non-neoplastic mucosa & 475 & 255 & 91 & 88 & 41 & 46.3 \\
\hline Adenoma & 126 & 53 & 27 & 30 & 16 & $57.9 *$ \\
\hline Primary cancer & 484 & 88 & 101 & 136 & 159 & $82.0 *$ \\
\hline Metastatic cancer in lymph node & 150 & 30 & 36 & 52 & 32 & 80.0 \\
\hline Metastatic cancer in liver & 21 & 4 & 5 & 7 & 5 & 81.0 \\
\hline
\end{tabular}

* compared with non-neoplastic mucosa, $\mathrm{p}<0.001$

$\mathrm{PR}$, positive rate

Table 2: Relationship between BTG3 expression and clinicopathological features of colorectal cancers

\begin{tabular}{|c|c|c|c|c|c|c|c|}
\hline \multirow{2}{*}{ Clinicopathological features } & \multirow{2}{*}{$\mathbf{n}$} & \multicolumn{6}{|c|}{ BTG3 expression } \\
\hline & & - & + & ++ & +++ & $\operatorname{PR}(\%)$ & $p$ value \\
\hline Age(years) & & & & & & & 0.090 \\
\hline$<65$ & 261 & 53 & 56 & 74 & 78 & 79.7 & \\
\hline$\geq 65$ & 223 & 35 & 45 & 62 & 81 & 84.3 & \\
\hline Sex & & & & & & & 0.946 \\
\hline male & 281 & 51 & 58 & 81 & 91 & 81.9 & \\
\hline Female & 203 & 37 & 43 & 55 & 68 & 81.8 & \\
\hline Depth of invasion & & & & & & & 0.030 \\
\hline $\mathrm{T}_{\mathrm{is}}-\mathrm{T}_{2}$ & 125 & 28 & 28 & 36 & 33 & 77.6 & \\
\hline $\mathrm{T}_{3}-\mathrm{T}_{4}$ & 339 & 52 & 70 & 97 & 120 & 84.7 & \\
\hline Lymphatic invasion & & & & & & & 0.322 \\
\hline- & 196 & 34 & 41 & 54 & 67 & 82.7 & \\
\hline+ & 208 & 38 & 47 & 65 & 58 & 81.7 & \\
\hline Venous invasion & & & & & & & 0.577 \\
\hline- & 193 & 39 & 39 & 57 & 58 & 79.8 & \\
\hline+ & 198 & 32 & 45 & 59 & 62 & 83.8 & \\
\hline Lymph node metastasis & & & & & & & 0.816 \\
\hline- & 255 & 46 & 55 & 67 & 87 & 82.0 & \\
\hline+ & 210 & 38 & 42 & 65 & 65 & 81.9 & \\
\hline Liver metastasis & & & & & & & 0.549 \\
\hline- & 449 & 81 & 94 & 130 & 144 & 82.0 & \\
\hline+ & 28 & 5 & 6 & 5 & 12 & 82.1 & \\
\hline Distant metastasis & & & & & & & 0.172 \\
\hline- & 444 & 81 & 94 & 129 & 140 & 81.8 & \\
\hline+ & 36 & 6 & 6 & 7 & 17 & 83.3 & \\
\hline
\end{tabular}

(Continued) 


\begin{tabular}{lccccccc}
\hline \multirow{2}{*}{ Clinicopathological features } & $\mathbf{n}$ & \multicolumn{7}{c}{ BTG3 expression } \\
\cline { 3 - 7 } & & - & + & ++ & +++ & PR(\%) & p value \\
\hline TNM staging & 244 & 44 & 54 & 65 & 81 & 82.0 & 0.861 \\
$\quad$ O-II & 218 & 38 & 42 & 68 & 70 & 82.6 & 0.037 \\
$\quad$ III-IV & & & & & & & \\
Differentiation & 196 & 30 & 37 & 57 & 72 & 84.6 & \\
$\quad$ Well-differentiated & 232 & 41 & 53 & 63 & 75 & 82.3 & \\
$\quad$ Moderately-differentiated & 32 & 8 & 9 & 9 & 6 & 75.0 & \\
$\quad$ Poorly-differentiated & & & & & & & \\
\end{tabular}

$\mathrm{PR}$, positive rate; $\mathrm{T}_{\mathrm{is}}$, cancer in situ; $\mathrm{T}_{1}$, lamina propria and submucosa; $\mathrm{T}_{2}$, muscularis propria; $\mathrm{T}_{3}$, subserosa and exposure to serosa; $\mathrm{T}_{4}$, invade other organs or perforate visceral peritoneum

Table 3: Multivariate analysis of clinicopathological variables for the survival of the patients with colorectal cancer

\begin{tabular}{lcc}
\hline Clinicopathological parameters & Relative risk (95\%CI) & p value \\
\hline Age $(\geq 65$ years) & $0.884(0.561-1.395)$ & 0.597 \\
Sex(Female) & $0.817(0.520-1.283)$ & 0.380 \\
Depth of invasion $\left(\mathrm{T}_{2-4}\right)$ & $5.873(2.058-16.762)$ & 0.001 \\
Lymphatic invasion $(+)$ & $1.269(0.756-2.129)$ & 0.367 \\
Venous invasion $(+)$ & $1.088(0.646-1.830)$ & 0.752 \\
Lymph node metastasis $(+)$ & $1.638(0.482-5.568)$ & 0.429 \\
Liver metastasis & $0.357(0.071-1.793)$ & 0.211 \\
Distant metastasis & $11.330(2.466-52.057)$ & 0.002 \\
TNM staging(I-II) & $1.746(0.453-6.729)$ & 0.418 \\
Differentiation (moderately and poorly) & $1.131(0.792-1.616)$ & 0.497 \\
BTG3 expression $(++\sim+++)$ & $1.227(0.775-1.942)$ & 0.384 \\
\hline
\end{tabular}

CI, confidence interval; TNM, tumor node metastasis

Although there in vivo and vitro appeared a low proliferation in $B T G 3$ transfecants, BTG3 overexpression resulted in $\mathrm{G}_{1}$ arrest in SW480 cells and S arrest in SW620 cells. Reportedly, Cyclin E and D1 activate Cdks and induce the transition between $\mathrm{G}_{1}$ and $\mathrm{S}$ phase [28]. Cyclin $\mathrm{B} 1-\mathrm{Cdk} 1$ is involved in the early events of mitosis and Cdc25B activates Cdc2 for the entry into mitosis [29]. Therefore, the higher expression of Cyclin D1, Cyclin E, cdc2 and cdk4 were responsible for S arrest in BTG3overxpressing SW620. Overexpressed p16 and p27 bind to cyclins and cdks, which cause $\mathrm{G}_{1}$ arrest $[28,30]$. Activated p53 binds DNA and activates expression of $\mathrm{p} 21$ to inhibit $\mathrm{G}_{1} / \mathrm{S}$ transition. BTG3-mediated cell cycle arrest might be due to the overexpression of above-mentioned 3 proteins.

BTG3 expression was found to positively associate with favorable prognosis of gastric and ovarian cancers $[13,16]$. Lv et al. [14] found that the hepatocellular cancer patients with lower BTG3 expression had shorter overall survival time than the ones with higher BTG3 expression. In contrast, no link between BTG3 expression and the survival time of the patients with CRC was demonstrated even though stratified according to depth of invasion, in line with our report of gastric cancer [18]. Multivariate analysis demonstrated that depth of invasion and distant metastasis were independent prognostic factors for overall CRCs. In our another report, a positive link between BTG1 expression and poor survival of gastric cancer patients was found, which depended upon invasive depth of the cancers [31]. These findings suggested that BTG3 expression could not be employed to indicate the prognosis of CRC patients.

In summary, down-regulated BTG3 expression might be positively correlated with the malignant transformation of colorectal epithelial cells and should be considered as a good biomarker for colorectal 
Table 4: The antibodies used in the present study

\begin{tabular}{|c|c|c|}
\hline Names & Source & Company \\
\hline BTG3 & Rabbit & Proteintech Biotech. Inc. \\
\hline Cyclin B1 (GNS1) & Mouse & Santa Cruz Biotech. Inc. \\
\hline CyclinE (HE12) & Rabbit & Santa Cruz Biotech. Inc. \\
\hline Cdc2 (B-6) & Mouse & Santa Cruz Biotech. Inc. \\
\hline $\mathrm{p} 27$ & Mouse & Santa Cruz Biotechnology \\
\hline Cyclin D1 (H-295) & Rabbit & Santa Cruz Biotech. Inc. \\
\hline XIAP(H-202) & Rabbit & Santa Cruz Biotech. Inc. \\
\hline $\operatorname{AIF}(E-1)$ & Mouse & Santa Cruz Biotech. Inc. \\
\hline $\mathrm{PI}_{3} \mathrm{~K}$ & Rabbit & Abcam \\
\hline Cdk4 (C-22) & Rabbit & Santa Cruz Biotech. Inc. \\
\hline $\mathrm{NF}-\kappa \mathrm{B}$ & Rabbit & Cell signaling \\
\hline Beclin 1 & Rabbit & Abcam \\
\hline $14-3-3(\mathrm{H}-8)$ & Mouse & Santa Cruz Biotechnology \\
\hline ATG14 & Rabbit & Cell signaling \\
\hline LC-3B & Rabbit & Wanleibio \\
\hline $\mathrm{Bcl}-2$ (C 21) & Rabbit & Santa Cruz Biotech. Inc. \\
\hline$\beta$-catenin $(C-18)$ & Goat & Santa Cruz Biotech. Inc. \\
\hline $\mathrm{p} 38 \alpha / \beta(\mathrm{H}-147)$ & Rabbit & Santa Cruz Biotech. Inc. \\
\hline p53 (FL-393) & Rabbit & Santa Cruz Biotech. Inc. \\
\hline p16(C-3) & Goat & Santa Cruz Biotech. Inc. \\
\hline$\beta-\operatorname{actin}(C-4)$ & Mouse & Santa Cruz Biotech. Inc. \\
\hline GAPDH & Rabbit & Wanleibio \\
\hline
\end{tabular}

carcinogenesis. Promoter methylation of BTG3 is partially responsible for its down- regulated expression. BTG3 overexpression might in vitro and vivo reverse the aggressive phenotypes of CRC cells and be employed as a target molecule for gene therapy.

\section{MATERIALS AND METHODS}

\section{Cell culture and transfection}

CRC cell lines were kindly presented by Prof. Miyagi, Clinical Research Institute, Kanagawa Cancer Center, Japan. They were cultured in RPMI 1640 (Colo201, Colo205, DLD-1. HCT-15, HCT-116, HT29, KM-12, SW480 and SW620) and DMEM (WiDr) medium added with $10 \% \mathrm{FBS}, 100$ units/mL penicillin, and $100 \mu \mathrm{g} / \mathrm{mL}$ streptomycin in an atmosphere of $5 \%$ $\mathrm{CO}_{2}$ at $37^{\circ} \mathrm{C}$. SW 480 and SW620 cells transfected with pcDNA3.1-BTG3 or pcDNA3.1 vector, and selected by G418 according to the manufacturer's instructions
(QIAGEN, USA). We treated CRC cells with 5-aza-20deoxycytidine (5-Aza-dC, DNA demethylating agent), cisplatin (a platinum- containing DNA crosslinker), MG132 (a proteasome inhibitor), paclitaxel (a mitotic inhibitor), and SAHA (a histone deacetylase inhibitor). All cells were pelleted by centrifugation, rinsed with PBS, and subjected to protein and RNA extraction.

\section{Proliferation assay}

Cell counting Kit-8 (CCK-8, Japan) was used to measure cell viability. Briefly, 4000cells/well were seeded on 96-well plate, which was added with $10 \mu \mathrm{L} \mathrm{CCK}-8$ solution at different time points. After the incubation for 3 $\mathrm{h}$, optical density was read without cover at $450 \mathrm{~nm}$.

\section{Cell cycle analysis}

The cells were harvested, washed by PBS and fixed in cold ethanol for $4 \mathrm{~h}$ at $-20^{\circ} \mathrm{C}$. After washed by PBS, 
the cells were immersed with $1 \mathrm{~mL}$ RNase $(0.25 \mathrm{mg} / \mathrm{mL})$ at $37^{\circ} \mathrm{C}$ for $1 \mathrm{~h}$. The cells were pelleted, resuspended in propidium iodide $(\mathrm{PI}, 50 \mu \mathrm{g} / \mathrm{mL})$ and incubated in the dark for $30 \mathrm{~min}$. Finally, flow cytometry was carried out to detect PI signal.

\section{Apoptosis assay}

Flow cytometry was carried out with PI and FITC-labeled Annexin V (KeyGEN Biotech) to examine apoptosis as the instructions recommend.

\section{Wound healing assay}

$1.0 \times 10^{6}$ cells/well was seeded in 6 -well culture plates, and scraped with a $100 \mathrm{uL}$ yellow pipette tip to create a scratch when they had grown to confluence at $80 \%$. After that, cells were washed by PBS and grown in FBS-free medium. Cells were photographed and the scratch area was calculated at the different time points using Image J software.

\section{Cell invasion assays}

For invasive assay, $2.5 \times 10^{5}$ cells were seeded in the matrigel-coated insert on the top of the chamber with serum-free medium. The low compartment was filled with $10 \%$-FBS medium as a chemoattractant. As a control, migration assay was performed except no matrigel coating. After incubated for $24 \mathrm{~h}$, cells on the membrane were scrubbed, washed with PBS, fixed in $100 \%$ methanol and stained with Giemsa dye for photography and measurement. Finally, the invasive rate was calculated as invasive cells/ migrative cells.

\section{ALP activity}

ALP activity was used as a marker of colorectal differentiation. Briefly, cells were harvested, homogenized and subjected to ALP activity and protein assays using Diagnostics ALP reagent (Sigma) and Biorad protein assay kit respectively. ALP activity was calculated as U per $\mu \mathrm{g}$ of protein.

\section{$\beta$-galactosidase staining}

$\beta$-galactosidase staining kit (Beyotime, Shanghai, China) was employed to indicate the senescence. The protocol was executed as recommended by the kit instruction.

\section{Metabolism assays}

Both oxygen consumption rates and extracellular acidification rates were measured in XF media (nonbuffered RPMI 1640 containing either $10 \mathrm{mM}$ or 25 $\mathrm{mM}$ glucose or galactose, $2 \mathrm{mM}$ L-glutamine, and $1 \mathrm{mM}$ sodium pyruvate) under basal conditions and in response to mitochondrial inhibitors, $1 \mathrm{mM}$ oligomycin and/or 100 $\mathrm{nM}$ rotenone $+1 \mathrm{mM}$ antimycin A (Sigma) on XF-96 Extracellular Flux Analyzers (Seahorse Bioscience).

\section{Luciferase reporter assay}

The luciferase reporter assay was performed using Dual-Luciferase ${ }^{\circledR}$ Reporter Assay System (Promega, USA) as recommended by the manufacturer. NF- $\kappa \mathrm{B}-$ mediated gene transcription activity was determined by the ratio of pGL3- NF- $\kappa$ B luciferase activity, which was normalized to Renilla luciferase activity of the control plasmid.

\section{Subjects}

Colorectal cancers $(n=484)$, adenoma $(n=126)$, adjacent NNM ( $n=475)$, metastatic foci in lymph node metastasis $(n=150)$ and in liver $(n=21)$ were collected from the surgical resection in the Affiliated Hospital of Kanagawa Cancer Center (Japan) between 1999 and 2008. The patients with CRC were 281 men and 203 women (26 85years, mean=64.1 years). Forty-five cases of CRCs and paired NNM were collected from the Shengjing Hospital of China Medical University (China) and frozen in $-80^{\circ} \mathrm{C}$ until use. None of the patients received chemotherapy, radiotherapy or adjuvant before surgery. All of them provided consent for use of tumor tissues for clinical research. Ethical Committee of our hospital and Kanagawa Cancer Center approved the research protocol. We followed up the patients by consulting their case documents or calling.

\section{Pathology}

All tissues were fixed in 10\% neutral formalin and prepared for paraffin-embedded block and $4 \mu \mathrm{m}$-thick section. These sections were subjected to hematoxylinand-eosin staining for routine pathological examination, including tumor size, depth of invasion, lymphatic and venous invasion, lymph node metastasis and liver metastasis. The staging for each colorectal cancer was evaluated according to tumor-node-metastasis system [32]. Histological architecture of CRCs was described in terms of WHO's classification [33].

\section{Xenograft models}

Locally bred female 6-week-old Balb/c nude mice were used for implantation. They were maintained under specific pathogen-free condition. Housing and all procedures were approved by the committee for animal experiments guidelines on animal welfare of our hospital. Xenografts were established by subcutaneous injection of $1 \times 10^{6}$ cells per mouse to axilla ( $\mathrm{n}=10$ mice /group). For each tumor, measurements were made using calipers, and 
tumor volumes were calculated as follows: width ${ }^{2} \times$ length $\times 0.52$. After anesthetization, the mice were photographed, and sacrificed. Tumors was weighted and cupped in PBS for the volume. After that, the part of tumors were fixed in $4 \%$ paraformaldehyde, and embedded in paraffin for following experiments.

\section{LCM and RNA extraction}

Colorectal cancer and glandular epithelial cells were dissected from $8-\mu \mathrm{m}$-thick and stained tissue slides (Staining Kit, Ambion) by an Arcturus Veritas ${ }^{\mathrm{TM}}$ laser capture microdissection system (Life Technologies) for total RNA extract using Pure Link RNA Mini Kit (Ambion).

\section{RT-PCR}

Total RNA was extracted from colorectal cancer cells or tissues using QIAGEN RNeasy mini kit (Germany), and subjected to cDNA synthesis using AMV transcriptase and random primers (Takara, Japan). According to the Genbank, oligonucleotide primers were designed as described previously [18]. General and realtime RT-PCR amplification was performed using Hotstart $\mathrm{Taq}^{\mathrm{TM}}$ polymerase and SYBR Premix Ex $\mathrm{Taq}^{\mathrm{TM}}$ II kit (Takara) respectively.

\section{Methylation-specific PCR (MSP)}

We extracted genomic DNA from colorectal cancer cells and tissues using QIAamp DNA Mini kit (QIAGEN). DNA was modified chemically with sodium metabisulphite using EZ DNA Methylation-Gold Kit (ZYMO Research). The bisulfite-modified DNA was amplified by using primer pairs that specifically amplify either methylated or unmethylated BTG3 as described previously [18].

\section{Western blot}

Denatured protein was separated on an SDSpolyacrylamide gel and transferred to Hybond membrane. The membrane was in turn blocked in 5\% skim milk, primary (Table 4) and secondary horseradish peroxidase (DAKO) antibody. Bands were visualized with Fuji4010 image system (GE Bioscience) by ECL-Plus detection reagents (Santa Cruz). Either $\beta$-actin or GAPDH was employed as the internal control antibody.

\section{Tissue microarray (TMA) and immunohistochemistry}

Two-mm-in-diameter TMA was prepared using a Tissue Microarrayer (AZUMAYA KIN-1, Japan). TMA was consecutively cut into $4-\mu \mathrm{m}$-thick sections, which were deparaffinised, rehydrated, and subjected to antigen retrieval in target retrieval solution (TRS, DAKO). The sections were quenched with $3 \%$ hydrogen peroxide and incubated with $5 \%$ bovine serum albumin. The sections were incubated with the rabbit antibody against BTG3 (Sigma; 1:100) or ki-67 (DAKO, 1:100), and then treated with the anti-rabbit conjugated to horseradish peroxidase (DAKO, USA) antibody. Binding sites were visualized with 3, 3'-diaminobenzidine. After counterstained with Mayer's hematoxylin, the sections were dehydrated, cleared and mounted. Omission of the primary antibody was used as a negative control.

BTG3 protein was positively localized in the cytoplasm, while ki-67 in nucleus. One hundred cells were randomly selected and counted from 5 representative fields of each section blindly by two independent observers (Zheng HC and Zhao S). The inconsistent data were determined for final agreement by both persons. The expression positivity was graded and counted as follows: 0 =negative; $1=1-50 \% ; 2=50-74 \% ; 3 \geq 75 \%$. The staining intensity score was graded as follows: $1=$ weak; 2 = intermediate; and $3=$ strong. The scores for BTG3 positivity and staining intensity were multiplied to obtain a final score, which determines their expression as $(-=0$; $+=1-2 ;++=3-5$; $+++=6-9$ ).

\section{Terminal digoxigenin-labeled dUTP nick-end labeling (TUNEL)}

Cell apoptosis was assessed using TUENL, a method that is based on the specific binding O-TdT to the 3-OH ends of DNA. Therefore, ApopTag Plus Peroxidase In Situ Apoptosis Detection Kit (Millipore) was used according to the recommendation. Omission of the working strength TdT enzyme was considered as a negative control.

\section{Oncomine analysis}

The individual gene expression level of BTG3 was analyzed using Oncomine (www.oncomine.org), a cancer microarray database and web-based data mining platform for a new discovery from genome-wide expression analyses. We compared the differences in BTG3 mRNA level between colorectal mucosa and adenoma/cancer. All data were log-transformed, median centered per array, and standard deviation normalized to one per array.

\section{Statistical analysis}

Spearman's correlation test and student t test were used to analyze the rank data and compare the means respectively. Kaplan-Meier survival plots were generated and comparisons between survival curves were made with the log-rank statistics. Cox's proportional hazards model was employed for multivariate analysis. SPSS 10.0 software was applied to analyze all data and $p<0.05$ was considered statistically significant. 


\section{ACKNOWLEDGMENTS}

This study was supported by Liaoning BaiQianWan Talents Program, Award for Liaoning Distinguished Professor, a Key Scientific and Technological Project of Liaoning Province (2015408001), a Research Grant of Natural Science Foundation of Liaoning Province (201602330) and National Natural Scientific Foundation of China (81472544; 81672700).

\section{CONFLICTS OF INTEREST}

The authors have declared that no competing interests exist.

\section{REFERENCES}

1. Papamichael D, Audisio RA, Glimelius B, de Gramont A, Glynne-Jones R, Haller D, Köhne CH, Rostoft S, Lemmens V, Mitry E, Rutten H, Sargent D, Sastre J, et al. Treatment of colorectal cancer in older patients. International Society of Geriatric Oncology (SIOG) consensus recommendations 2013. Ann Oncol. 2015; 26:463-476.

2. Cancer facts and figures. American Cancer Society, 2014 edition.

3. Winkler GS. The mammalian anti-proliferative BTG/Tob protein family. J Cell Physiol. 2010; 222: 66-72.

4. Guéhenneux F, Duret L, Callanan MB, Bouhas R, Hayette S, Berthet C, Samarut C, Rimokh R, Birot AM, Wang Q, Magaud JP, Rouault JP. Cloning of the mouse BTG3 gene and definition of a new gene family (the BTG family) involved in the negative control of the cell cycle. Leukemia. 1997; 11:370-375.

5. Ou YH, Chung PH, Hsu FF, Sun TP, Chang WY, Shieh SY. The candidate tumor suppressor BTG3 is a transcriptional target of p53 that inhibits E2F1. EMBO J.2007; 26: 3968-3980.

6. Miyai K, Yoneda M, Hasegawa U, Toita S, Izu Y, Hemmi H, Hayata T, Ezura Y, Mizutani S, Miyazono K, Akiyoshi $\mathrm{K}$, Yamamoto T, Noda M. ANA deficiency enhances bone morphogenetic protein- induced ectopic bone formation via transcriptional events. J Biol Chem. 2009; 284: 10593-10600.

7. Rahmani Z. APRO4 negatively regulates Src tyrosine kinase activity in PC12 cells. J Cell Sci. 2006; 119: 646-658.

8. Cheng YC, Lin TY, Shieh SY. Candidate tumor suppressor BTG3 maintains genomic stability by promoting Lys63linked ubiquitination and activation of the checkpoint kinase CHK1. Proc Natl Acad Sci U S A. 2013; 110:5993-5998.

9. Yoneda M, Suzuki T, Nakamura T, Ajima R, Yoshida Y, Kakuta S, Sudo K, Iwakura Y, Shibutani M, Mitsumori K, Yokota J, Yamamoto T. Deficiency of antiproliferative family protein Ana correlates with development of lung adenocarcinoma. Cancer Sci. 2009; 100: 225-232.

10. Yu J, Zhang Y, Qi Z, Kurtycz D, Vacano G, Patterson D. Methylation-mediated downregulation of the B-cell translocation gene 3 (BTG3) in breast cancer cells. Gene Expr. 2008; 14:173-182.

11. Majid S, Dar AA, Shahryari V, Hirata H, Ahmad A, Saini S, Tanaka Y, Dahiya AV, Dahiya R. Genistein reverses hypermethylation and induces active histone modifications in tumor suppressor gene B-Cell translocation gene 3 in prostate cancer. Cancer. 2010; 116: 66-76.

12. Majid S, Dar AA, Ahmad AE, Hirata H, Kawakami K, Shahryari V, Saini S, Tanaka Y, Dahiya AV, Khatri G, Dahiya R. BTG3 tumor suppressor gene promoter demethylation, histone modification and cell cycle arrest by genistein in renal cancer. Carcinogenesis. 2009; 30: 662-670.

13. Ren XL, Zhu XH, Li XM, Li YL, Wang JM, Wu PX, Lv ZB, Ma WH, Liao WT, Wang W, Ding YQ, Liang L. Downregulation of BTG3 promotes cell proliferation, migration and invasion and predicts survival in gastric cancer. $\mathrm{J}$ Cancer Res Clin Oncol. 2015; 141: 397-405.

14. Lv Z, Zou H, Peng K, Wang J, Ding Y, Li Y, Ren X, Wang F, Chang R, Liang L, Ding Y. The suppressive role and aberrent promoter methylation of BTG3 in the progression of hepatocellular carcinoma. PLoS One. 2013; 8:e77473.

15. Chen X, Chen G, Cao X, Zhou Y, Yang T, Wei S. Downregulation of BTG3 in non-small cell lung cancer. Biochem Biophys Res Commun. 2013; 437:173-178.

16. Deng B, Zhao Y, Gou W, Chen S, Mao X, Takano Y, Zheng H. Decreased expression of BTG3 was linked to carcinogenesis, aggressiveness, and prognosis of ovarian carcinoma. Tumour Biol. 2013; 34:2617-2624.

17. Yanagida S, Taniue K, Sugimasa H, Nasu E, Takeda Y, Kobayashi M, Yamamoto T, Okamoto A, Akiyama T. ASBEL, an ANA/BTG3 antisense transcript required for tumorigenicity of ovarian carcinoma. Sci Rep. 2013; $3: 1305$.

18. Gou WF, Yang XF, Shen DF, Zhao S, Liu YP, Sun HZ, Takano Y, Su RJ, Luo JS, Zheng HC. The roles of BTG3 expression in gastric cancer: a potential marker for carcinogenesis and a target molecule for gene therapy. Oncotarget. 2015; 6: 19841-19867. doi: 10.18632/oncotarget.3734.

19. Du Y, Liu P, Zang W, Wang Y, Chen X, Li M, Zhao G. BTG3 upregulation induces cell apoptosis and suppresses invasion in esophageal adenocarcinoma. Mol Cell Biochem. 2015; 404:31-38.

20. Sasajima H, Nakagawa K, Yokosawa H. Antiproliferative proteins of the BTG/Tob family are degraded by the ubiquitin-proteasome system. Eur J Biochem. 2002; 269: 3596-3604.

21. Provenzani A, Fronza R, Loreni F, Pascale A, Amadio M, Quattrone A. Global alterations in mRNA polysomal 
recruitment in a cell model of colorectal cancer progression to metastasis. Carcinogenesis. 2006; 27: 1323-1333.

22. Cheng YC, Chen PH, Chiang HY, Suen CS, Hwang MJ, Lin TY, Yang HC, Lin WC, Lai PL, Shieh SY. Candidate tumor suppressor B-cell translocation gene 3 impedes neoplastic progression by suppression of AKT. Cell Death Dis. 2015; 6: e1584.

23. Mao D, Qiao L, Lu H, Feng Y. B-cell translocation gene 3 overexpression inhibits proliferation and invasion of colorectal cancer SW480 cells via Wnt/ $\beta$-catenin signaling pathway. Neoplasma. 2016; 63:705-716.

24. Huang Y. Pharmacogenetics/genomics of membrane transporters in cancer chemotherapy. Cancer Metastasis Rev. 2007; 26:183-201.

25. Yuge K, Kikuchi E, Hagiwara M, Yasumizu Y, Tanaka N, Kosaka T, Miyajima A, Oya M. Nicotine induces tumor growth and chemoresistance through activation of the PI3K/ Akt/mTOR pathway in bladder cancer. Mol Cancer Ther. 2015; 14:2112-2120.

26. Cosentino K. García-Sáez AJ. Mitochondrial alterations in apoptosis. Chem Phys Lipids. 2014; 181:62-75.

27. Smolewski P. Robak T. Inhibitors of apoptosis proteins (IAPs) as potential molecular targets for therapy of hematological malignancies. Curr Mol Med. 2011; 11: 633-649.

28. Williams G, Stoeber K. The cell cycle and cancer. J Pathol. 2012; 226:352-364.

29. Bretones G. Dolores Delgado M. León J. Myc and cell cycle control. Biochim Biophys Acta. 2015; 1849: 506-516.

30. Cmielová J, Rezáčová M. p21Cip1/Waf1 protein and its function based on a subcellular localization. J Cell Biochem. 2011; 112: 3502-3506.

31. Zheng HC, Li J, Shen DF, Yang XF, Zhao S, Wu YZ, Takano Y, Sun HZ, Su RJ, Luo JS, Gou WF. BTG1 expression correlates with pathogenesis, aggressive behaviors and prognosis of gastric cancer: a potential target for gene therapy. Oncotarget. 2015; 6: 19685-19705. doi: 10.18632/ oncotarget.4081.

32. Sobin LH, Wittekind CH. TNM Classification of Malignant Tumours, 6th edition, John Wiley \& Sons, Hoboken, New Jersey, USA, 2000.

33. Hamilton SR, Aaltonen LA. WHO classification of tumors: pathology and genetics of tumors of the digestive system. IARC press, lyon, 2000. 